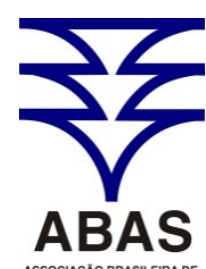

ASSOCIACĀOB BRASILEIRADE
AGUAS SUBTERRANEAS www.abas.org

\section{MODELO HIDROGEOLÓGICO CONCEITUAL DO SISTEMA AQUÍFERO URUCUIA CENTRO-OCIDENTAL, BRASIL}

\author{
CONCEPTUAL HYDROGEOLOGIC MODEL OF CENTRAL-WESTERN URUCUIA \\ AQUIFER SYSTEM, BRAZIL
}

Natanael da Silva Barbosa'; Luiz Rogério Bastos Leal²; José de Castro Mello; Marco Antônio Lima Peixinho4; Cristovaldo Bispo dos Santos ${ }^{5}$; Rafael Lima dos Santos Santos ${ }^{6}$; Natali da Silva Barbosa ${ }^{5}$

Artigo recebido em: 22/11/2015 e aceito para publicação em: 05/11/2016.

DOI: http://dx.doi.org/10.14295/ras.v31i1.28524

Resumo: O Sistema Aquífero Urucuia (SAU) representa um conjunto de aquíferos inter-relacionados associados às rochas sedimentares do Grupo Urucuia. Cinco perfis geofísicos de poços foram interpretados e subsidiaram a elaboração do modelo hidrogeológico conceitual. Três eletrofácies são identificadas: (i) substrato regional do Grupo Bambuí; (ii) sistema eólico da Formação Posse e; (iii) sistema fluvial entrelaçado da Formação Serra das Araras segmentados por níveis tabulares de arenitos maciços e silicificados. No contexto hidrogeológico, a posição estratigráfica dos níveis de arenitos silicificados em relação àquelas do nível freático regional condiciona a ocorrência de aquíferos não-confinados quando disposto acima, e um sistema aquífero-aquitarde-aquífero quando abaixo. Nesse contexto, o aquífero confinado inferior apresenta cargas hidráulicas maiores do que as verificadas no livre sobrejacente. Os horizontes de arenitos silicificados funcionam como aquitardes e dispõem-se mais profundos e espessos na porção centro-ocidental. Adicionalmente, os valores da porosidade efetiva e coeficiente de armazenamento variam entre $10^{-2}$ a $10^{-1}$ e $10^{-4}$. Já as transmissividades variam entre $10^{-4}$ a $10^{-6}$ e $10^{-3} \mathrm{~m}^{2} / \mathrm{s}$ para os subtipos não-confinado e confinado, respectivamente. No extremo ocidental, o SAU exibe poços cujos níveis estáticos são profundos (acima de $100 \mathrm{~m}$ ) como consequência de um divisor de água subterrânea na bacia hidrogeológica. Em geral, os rebaixamentos produzidos, após os ensaios de bombeamento dos poços, diminuem progressivamente em direção à porção centro-ocidental do SAU, aliado a um aumento da capacidade específica dos poços, da espessura saturada e da potencialidade hidrogeológica.

Palavras-Chave: Sistema Aquífero Urucuia. Perfis geofísicos de poços. Modelo hidrogeológico conceitual.

Abstract: The Urucuia Aquifer System (UAS) is a set of interrelated aquifers associated with the sedimentary rocks of Urucuia Group. Five geophysical well logs were interpreted and supported the development of conceptual hydrogeologic model. Three electrofacies are identified: (i) regional substrate of Bambuí Group; (ii) eolian system of Posse Formation; (iii) braided fluvial system of Serra das Araras Formation targeted by tabular levels of massive and silicified sandstones. In the hydrogeological context, the stratigraphic position of the silicified sandstones levels in relation to the regional groundwater level leads to the occurrence of unconfined aquifers when it is disposed above, and an aquifer-aquitard-aquifer system when it is located below. In this context, the lower confined aquifer presents hydraulic heads greater than the ones in the overlying unconfined. Silicified sandstones horizons function as aquitards and have become more deep and thick in the central-western portion. Additionally, the effective porosity and storage coefficient values ranging from $10^{-2}$ to $10^{-1}$ and $10^{-4}$, while the transmissivity between $10^{-6}$ and $10^{-4}$ to $10^{-3} \mathrm{~m}^{2} / \mathrm{s}$ for unconfined and confined subtypes, respectively. In the extreme west, the UAS displays wells whose static levels are deep (over $100 \mathrm{~m}$ ), because of a groundwater divider the hydrogeological basin. In general, the drawdowns produced after the pumping test wells gradually decrease toward SAU western-central portion, combined with an increase of the specific capacity of the wells, the saturated thickness and hydrogeological potential.

Keywords: Urucuia Aquifer System. Geophysical well logs. Conceptual hydrogeologic model.

1,2,5,7 Universidade Federal da Bahia (UFBA), Salvador, BA - E-mails: (nlsb2@yahoo.com.br, lrogerio@ufba.br, bispo@ufba.br, natali@usp.br)

3,4 Companhia de Engenharia Hídrica e Saneamento da Bahia - E-mails: (castromello@yahoo.com.br, mpeixinho@ufba.br)

$6 \quad$ Universidade Federal do Oeste da Bahia - E-mail: (rafael_lss@hotmail.com) 


\section{INTRODUÇÃO}

O Sistema Aquífero Urucuia corresponde a um conjunto de aquíferos inter-relacionados associados às rochas sedimentares do Grupo Urucuia (SAU) (GASPAR, 2006; GASPAR e CAMPOS, 2007). Representa um dos mais importantes mananciais de água subterrânea do Brasil, distribuindo-se por seis estados brasileiros (i.e., Bahia, Tocantins, Minas Gerais, Piauí, Maranhão e Goiás). Possui área de aproximadamente $120.000 \mathrm{~km}^{2}$ e espessura de rochas sedimentares que pode atingir valores superiores a $600 \mathrm{~m}$ (GASPAR et al., 2012). É responsável por cerca de $90 \%$ da descarga de base dos rios da região oeste da Bahia (PIMENTEL et al., 2000). Seu fluxo de base mantém a perenidade e a alta vazão dos rios afluentes nas bacias hidrográficas dos rios São Francisco e Tocantins-Araguaia, durante o período de recessão das chuvas, entre os meses de abril e outubro (GASPAR, 2006).

O aumento na demanda de água para irrigação e atividades agroindustriais, nos últimos 30 anos, levou alguns mananciais superficiais (e.g., rio das Fêmeas, rio Grande) a uma situação crítica quanto à sua disponibilidade hídrica e à consequente negação de novas outorgas para captação de água. Este fato tem conduzido os segmentos produtivos a intensificar a explotação e uso das águas subterrâneas através da perfuração de poços tubulares profundos (SCHUSTER et al., 2002; GASPAR, 2006; BARBOSA et al., 2014). Atualmente, embora conhecido regionalmente como um excelente sistema aquífero, tanto em relação às reservas quanto à produtividade dos poços, ainda inexiste no meio técnico/científico a proposição de um modelo conceitual que sirva como base para as interpretações hidrogeológicas. Nesse sentido, este artigo tem como objetivo apresentar os resultados de pesquisa que buscou elaborar um modelo hidrogeológico do SAU através de dados geológicos de campo, hidrogeológicos e de perfis geofísicos de poços.

\section{CONTEXTO GEOLÓGICO E HIDRO- GEOLÓGICO REGIONAL}

O Grupo Urucuia representa a unidade geológica neocretácea da Bacia Sanfranciscana (BS) (i.e., depressão intracontinental onde se acumularam as coberturas sedimentares fanerozoicas sobre o Cráton do São Francisco) (SGARBI, 1989). Possui maiores espessuras, distribuição em área e potencialidade hidrogeológica na porção centro-setentrional da BS, onde ocorre de forma contínua (Figura 1). Na porção meridional é segmentado e descontínuo (CAMPOS e DARDENNE, 1999). Em geral, apresenta relevo plano e suavemente inclinado para leste, na forma de extensas chapadas limitadas por escarpas nos extremos ocidentais e orientais. Os afloramentos, quando existentes, estão localizados nas quebras de relevo e nos cursos dos rios. A presença de testemunhos isolados demonstra que, provavelmente, sua área deposicional era mais extensa do que aquela atualmente observada. As espessuras sedimentares, ainda motivo de muitas investigações (e.g., LIMA, 2000; AMORIM JÚNIOR, 2003; BONFIM e GOMES, 2004; TSCHIEDEL, 2004; AMORIM JÚNIOR e LIMA, 2007; KIANG e SILVA, 2015), aumentam gradualmente de sul para o centro-norte.

A unidade, na maior parte da bacia, assenta-se diretamente sobre o substrato regional representado pelo Grupo Bambuí, podendo também recobrir localmente faixas granito-gnáissicas arqueanas e outras unidades sedimentares fanerozoicas da BS. Na porção setentrional, por sua vez, sobrepõe-se aos sedimentos paleozoicos da Bacia do Parnaíba (Figura 01). As diferenças nos tipos litológicos e no padrão de sedimentação possibilitam a distinção de duas unidades litoestratigráficas: a inferior, Formação Posse e a superior, Formação Serra das Araras (CAMPOS e DARDENNE, 1997; CAMPOS e DARDENNE, 1999). 


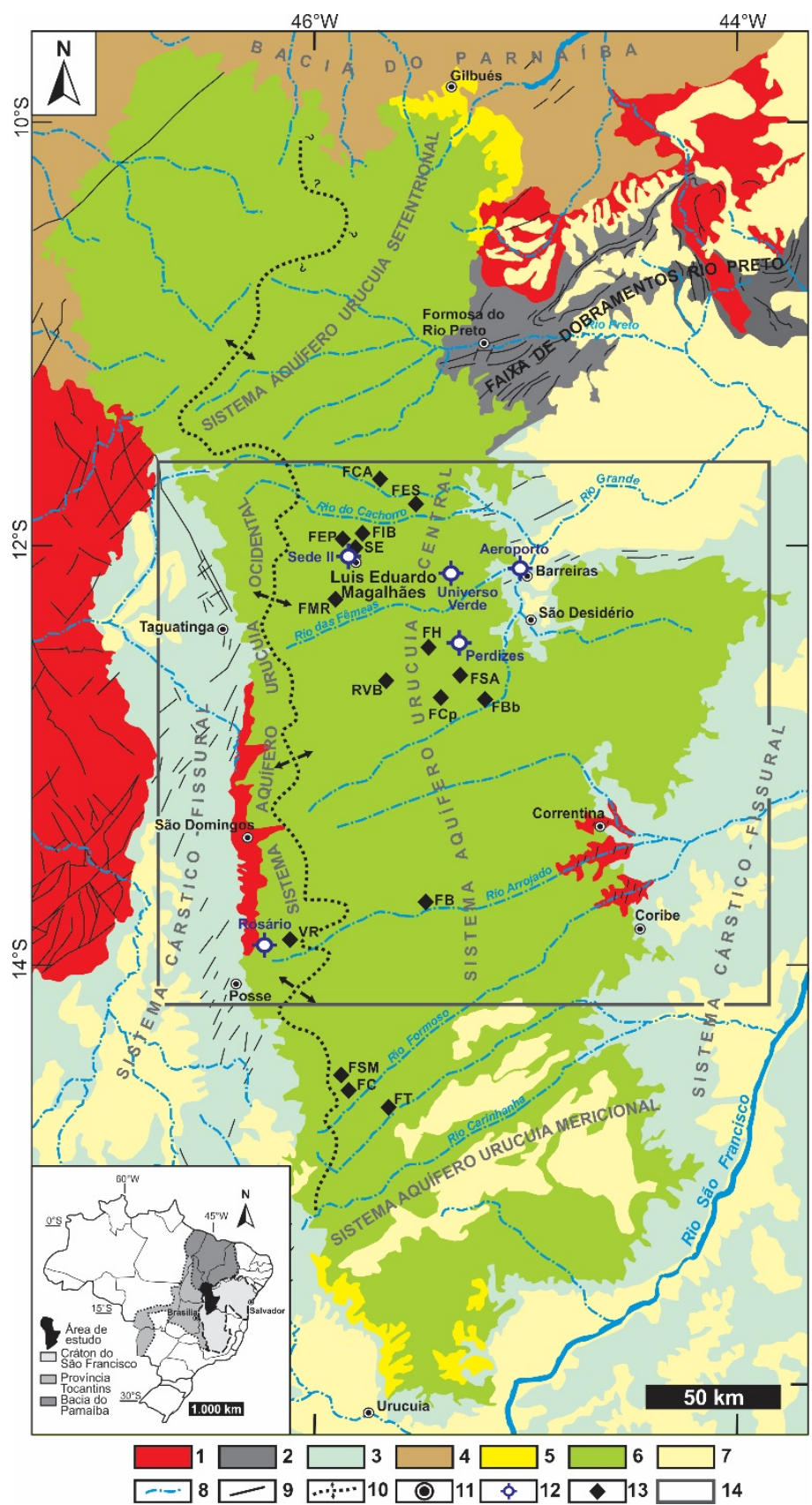

Figura 1 - Mapa geológico destacando a área de abrangência dos poços onde foram realizados os principais testes de bombeamento e perfilagem geofísica no Sistema Aquífero Urucuia Centro-Ocidental e o substrato regional. 1 Embasamento arqueano; 2 - Grupo Rio Preto; 3 - Grupo Bambuí; 4 - Sedimentos paleozoicos da Bacia do Parnaíba; 5 - Grupo Areado; 6 - Grupo Urucuia; 7 - Coberturas detrito-lateríticas; 8 - Rios; 9 - Lineamentos, 10 Divisor de água subterrânea, 11 - Sedes Municipais, 12 - Poços perfilados; 13 - Poços com testes de bombeamento; 14 - Área de abrangência dos poços perfilados; FCA - Faz. Campo Aberto; FES - Faz. Espírito Santo; FEP - Faz. Poletto; FCp - Faz. Campinas; FSA - Faz. Sto. Antônio; FIB - Faz. Isís Basso; SE - Sede Embasa; FMR - Faz. Marechal Rondon; FH - Faz. Hirata; RVB - Roda Velha de Baixo; FBb - Faz. Bombarda; FB - Faz. Buriti; FC - Faz. COBA; FSM - Faz. São Miguel; FT - Faz. Trijunção; VR - Vila Rosário

Figure 1. Geologic map highlighting the coverage area of the wells where the main pumping tests and geophysical loggings were performed in the Western-Central Urucuia Aquifer System and regional substrate. 1 Archean Basement; 2 - Rio Preto Group; 3 - Bambuí Group; 4 - Paleozoic sediments of the Parnaíba Basin; 5 - Areado Group; 6 - Urucuia Group; 7 - Detritus-lateritic covers; 8 - Rivers; 9 - Lineaments; 10 - Groundwater divider; 11 - Municipal seats; 12 - Wells logs; 13 - Wells with pumping tests; 14 - Coverage area of the wells loggings; FCA Campo Aberto Farm; FES - Espírito Santo Farm; FEP - Poletto Farm; FCp - Campinas Farm; FSA - Sto. Antônio Farm; FIB - Isís Basso Farm; SE - Sede Embasa; FMR - Marechal Rondon Farm; FH - Hirata Farm; RVB Roda Velha de Baixo; FBb - Bombarda Farm; FB - Buriti Farm; FC - COBA Farm; FSM - São Miguel Farm; FT - Trijunção Farm; VR - Vila Rosário 


\subsection{Formação Posse}

A Formação Posse é constituída por arenitos de cores amarela, rosa e avermelhadas, muito finos, finos a médios, bem selecionados e maturos textural e mineralogicamente. É comum a presença de uma fina película de óxidos/hidróxidos de ferro em torno dos grãos de quartzo detríticos (i.e., red beds). Apresenta estratificações cruzadas tangenciais de grande porte, com espessura dos sets de aproximadamente $20 \mathrm{~m}$, geralmente truncados por planos horizontais, representados por estratificações horizontais e de baixo ângulo. As estruturas sedimentares, aliadas à maturidade textural, representam feições diagnósticas de um ambiente desértico de campo de dunas (i.e., um grande $\operatorname{erg}$ que se estendia até além dos limites com a Bacia do Parnaíba) composto de sucessões de dunas e interdunas, no qual o nível freático encontrava-se abaixo da superfície deposicional (i.e., sistema eólico seco) (BARBOSA et al., 2011; CAMPOS e DARDENNE, 1994; CAMPOS e DARDENNE, 1997; CAMPOS e DARDENNE, 1999; SPIGOLON e ALVARENGA, 2002).

A transição entre as unidades é caracterizada por uma superfície que separa o sistema eólico (Formação Posse) do sistema fluvial-eólico (Formação Serra das Araras), marcando o início de períodos mais úmidos, implicando em uma imediata flutuação do nível de base (SPIGOLON e ALVARENGA, 2002).

\subsection{Formação Serra das Araras}

A Formação Serra das Araras é constituída por ciclos de sedimentação superpostos, composto por conglomerados, arenitos e argilitos, intercalados em bancos plano-paralelos, com espessuras variando de $50 \mathrm{~cm}$ a $2 \mathrm{~m}$. As sequências com padrão textural de granodecrescência ascendente são formadas na base por níveis conglomeráticos avermelhados, com seixos de quartzo, quartzitos, arenitos da própria sequência e feldspatos caolinizados. Representam canais temporários preenchidos por fluxos de detritos com alta descarga de sedimentos em regime de fluxo superior de alta energia (SPIGOLON e ALVARENGA, 2002). Durante a sedimentação, um processo de infiltração mecânica das argilas ocorre nos sedimentos eólicos subjacentes (CAMPOS e DARDENNE, 1999). Em seguida, ocorrem arenitos vermelhos com níveis amarelados, polimodais, regionalmente com horizontes silicificados, onde, em direção ao topo da sucessão, as estratificações cruzadas acanaladas de pequeno porte são sobrepostas por laminações plano-paralelas. Evidências de silicificação nos arenitos são verificadas em várias posições estratigráficas e em níveis tabulares (de até $8 \mathrm{~m}$ ) extensos e descontínuos (CAMPOS e DARDENNE, 1999). Na porção superior ocorrem horizontes pelíticos avermelhados de até $20 \mathrm{~cm}$ de espessura, compactos e brechados com gretas de contração, representando um transporte dominantemente suspensivo desenvolvido em amplas e rasas planícies de inundação.

Não se descarta a possibilidade de associações de lagos rasos intermitentes com os depósitos fluviais. O conjunto dessas litofácies representam modificações no regime de fluxo em ambientes fluviais entrelaçados desenvolvidos em amplas planícies com uma grande variação de descarga provavelmente em fácies de wadi fans (BORGES et al., 1992; CAMPOS e DARDENNE, 1997; CAMPOS e DARDENNE, 1999; SPIGOLON e ALVARENGA, 2002).

\subsection{Hidrogeologia}

O SAU é representado por um conjunto de aquíferos intergranulares dispostos na forma de um extenso tabuleiro com uma área efetiva de aproximadamente $76.000 \mathrm{~km}^{2}$ (GASPAR e CAMPOS, 2007). Em geral, apresenta maiores espessuras saturadas e potencialidade hídrica nas porções centro-ocidental (AMORIM JR e LIMA, 2007; GASPAR et al., 2012; MARTINS e CARDOSO, 2012; BARBOSA et al., 2014).

É uma bacia hidrogeológica assimétrica devido à presença, no extremo ocidental, de um divisor do fluxo subterrâneo de direção aproximadamente norte-sul (Figura 1). Essa feição proporciona uma rápida depleção da 
superfície potenciométrica e recarga das nascentes situadas nas quebras de relevo que as limitam. Seu posicionamento aproximado foi demarcado com base nas informações de levantamentos geofísicos elétricos (LIMA, 2000; AMORIM JUNIOR, 2003; AMORIM JUNIOR E LIMA, 2007; LIMA e SANTOS, 2011; BARBOSA et al., 2014) e dados de nível estático dos poços cadastrados na região. A oeste do eixo divisor, os níveis potenciométricos são mais profundos (atingem cerca de $180 \mathrm{~m}$ ) (GASPAR e CAMPOS, 2007, BARBOSA et al., 2014). Nessa bacia hidrogeológica, o mecanismo de recarga da água subterrânea ocorre predominantemente devido a infiltração das águas das chuvas, onde as alturas pluviométricas médias apresentam os maiores valores (isoietas normalmente superiores a $1.000 \mathrm{~mm}$ por ano) (GASPAR e CAMPOS, 2007).

Os parâmetros hidrodinâmicos obtidos através de ensaios de bombeamento realizados em diferentes sub-bacias hidrográficas revelam dois conjuntos de resultados: (i) altos valores de transmissividade (T), entre $10^{-2}$ a $10^{-3} \mathrm{~m}^{2} / \mathrm{s}$, condutividade hidráulica $(\mathrm{K})$ da ordem de $10^{-4}$ a $10^{-6} \mathrm{~m} / \mathrm{s}$ e coeficiente de armazenamento da ordem de $10^{-3}$ a $10^{-5}$ para o aquífero confinado (Tabela 1) (SANTOS, 2002; SCHUSTER et al., 2002; SCHUSTER et al., 2003; GASPAR, 2006; POMPEU e RODRIGUES, 2002; BARBOSA, 2009; CAMPOS et al., 2010). Nesse tipo aquífero, as elevadas vazões de explotação associadas a pequenos rebaixamentos observados nos poços resultam no desenvolvimento de extensos raios de influência (acima de $2.500 \mathrm{~m}$ ), acarretando em interferências entre os poços e desses com os cursos de águas superficiais nas épocas de estresse hídrico (meses de maio a outubro) (BARBOSA et al., 2014) e (ii) menores valores de $\mathrm{T}$, entre $10^{-2}$ a $10^{-5} \mathrm{~m}^{2} / \mathrm{s}$ ), $\mathrm{K}$ de $10^{-4}$ a $10^{-}$ ${ }^{7} \mathrm{~m} / \mathrm{s}$ e porosidade efetiva $\left(\mathrm{S}_{\mathrm{y}}\right)$ da ordem de $10^{-}$ ${ }^{2}$ para aquífero livre (SANTOS, 2002; GASPAR, 2006; BARBOSA, 2009; CAMPOS et al., 2010) (Tabela 1). Em geral, seu fluxo de base mantém a perenidade da rede de drenagem, que contribui efetivamente na regularização da vazão do médio rio São Francisco no período de recessão das chuvas (GASPAR e CAMPOS, 2007).

A hidrogeologia do SAU ainda é objeto de muitos questionamentos e investigações quanto à sua espessura, tipos de aquíferos existentes e suas inter-relações. Várias ideias foram propostas tendo como suporte os valores de parâmetros hidrodinâmicos obtidos a partir de dados de testes de bombeamento em diferentes sub-bacias hidrográficas: (i) aquífero inferior do tipo drenante ou semi-confinado, o qual recebe um fluxo vertical (ou drenança) do aquífero superior do tipo arenito fraturado e não-confinado (SCHUSTER, 2003; SCHUSTER et al., 2002); (ii) aquífero livre com drenança retardada (NASCIMENTO, 2003; LUZ et al., 2009; CAMPOS et al., 2010); (iii) presença de sub-tipos de aquíferos (i.e., livre, confinado, livre profundo e suspenso) devido a modificações no padrão de sedimentação do Grupo Urucuia (GASPAR, 2006; GASPAR e CAMPOS, 2007); (iv) sistema livre desenvolvido nos intervalos arenosos superiores e condições locais de confinamento, nos mesmos arenitos, controlado por intervalos arenosos muito silicificados (OLIVEIRA et al., 2008; LIMA e SANTOS, 2011); (v) aquífero livre superior com dupla porosidade (granular e fissural) e um semiconfinado inferior de porosidade granular, sem nenhum aquitarde entre eles (RODRIGUES et al., 2009); (vi) sistema aquíferoaquitarde-aquífero representado por um aquífero inferior do tipo confinado, um aquitarde formado por níveis de arenitos silicificados e fraturados e um aquífero superior do tipo livre, não sendo descartada a hipótese de ocorrência de drenança a partir dos arenitos silicificados (BARBOSA, 2007; BARBOSA, 2009; BARBOSA et al., 2014); (vii) diferentes comportamentos hidrogeológicos a depender da posição na bacia (BARBOSA et al., 2010) e; (viii) um dos mais expressivos aquíferos de natureza livre do Brasil (KIANG e SILVA, 2015).

\section{MÉTODOS}

Os estudos hidrogeológicos foram de- 
senvolvidos segundo uma sequência metodológica que se inicia por etapas de levantamento bibliográfico, aquisição de dados hidrogeológicos, reconhecimento de campo e interpretação de perfis geofísicos de poços e de ensaios de bombeamento e elaboração do modelo hidrogeológico conceitual. Neste trabalho foram utilizados dados secundários de poços da CERB (Companhia de Engenharia Hídrica e de Saneamento da Bahia) (i.e., Barreiras-Aeroporto, Barreiras-Universo Verde, Luís Eduardo Magalhães-Sede, CorrentinaRosário) e da SRH-BA (Secretaria de Recursos Hídricos do Estado da Bahia) (i.e., São Desidério-Perdizes).

A interpretação dos perfis geofísicos objetiva a determinação das eletrofácies, que auxiliam na definição dos contatos, na interpretação litológica e na correlação poço a poço. Todos os poços foram perfilados e processados pela HIDROLOG Serviços de Perfilagem e as curvas produzidas pelo software HYDROLOG $^{\mathrm{TM}}$ com dados de profundidade, raios gama (GR), potencial espontâneo (SP), sônico (DT) e indução (DIR) e normal curta (SN) através de um arquivo digital em formato LAS (Log ASCII Standard) e normatizadas em padrão API (American Petroleum Institute).

A distinção entre ambientes e de processos sedimentares é realizada pela observação do formato da curva do perfil RG. Na ausência de condições favoráveis, é necessário o uso da resistividade profunda (DIR) e do potencial espontâneo (SP). Eventualmente, pode-se utilizar a curva SN, embora não seja aconselhável por sofrer fortes influências ambientais (e.g., lama e/ou invasão do filtrado).

Quantitativamente, os perfis de resistividade investigam volumes radiais distintos de rocha, ou seja, a DIR analisa a zona virgem e a SN, a zona lavada. Qualitativamente, a integração dessas informações possibilita a identificação de camadas impermeáveis (e.g., folhelhos) com baixos valores DIR e SN, ausência de invasão e eventual superposição entre as curvas. Já em camadas permoporosas ocorre uma separação devido ao processo de invasão de fluidos de perfuração (i.e., presença de água da formação e filtrado). O SP é pouco confiável e utilizado, devido à incorporação de potenciais telúricos ou originados próximos à superfície. Já os dados DT são importantes na determinação de processos de cimentação, compactação dos sedimentos e da profundidade do nível freático. Na prática, o ideal é uma interpretação baseada na conjunção da maior quantidade possível de curvas (NERY e BARROS, 2000).

Ressalta-se a dificuldade de estabelecimento dos contatos entre as unidades geológicas com a interpretação dos perfis, devido à presença de uma sucessão predominantemente de arenitos e à relativa ausência de contraste entre os diferentes parâmetros analisados, sendo que esses foram inferidos e auxiliados com dados estratigráficos de campo. Em contrapartida, a caracterização hidrogeológica mostrou-se favorável por meio da identificação das zonas de arenitos silicificados nos perfis DT e sua relação com a posição do nível freático no estabelecimento dos diferentes subtipos aquíferos do SAU.

Os dados de ensaios de bombeamento foram obtidos do banco de dados da CERB. Foram realizados com duração de 24 horas em poços parcialmente penetrantes (exceto àquele do poço Barreiras-Aeroporto), com posterior recuperação do nível dinâmico. Em todos os testes, as condições de regime estacionário foram alcançadas.

A interpretação dos dados foi realizada utilizando os métodos de Hantush e Jacob (1955) para aquíferos confinados drenantes e Neuman (1975) para aquíferos livres, com o objetivo de determinar os parâmetros hidrodinâmicos (i.e., condutividade hidráulica, transmissividade e coeficiente de armazenamento/porosidade efetiva), de forma a caracterizar as condições hidrogeológicas das diferentes unidades aquíferas do SAU associadas à evolução temporal dos rebaixamentos produzidos. Já as cargas hidráulicas (i.e., altura de elevação do nível da água de um poço em relação a um datum arbitrário) foram determinadas a partir dos dados hidrogeológicos dos poços supracitados (Tabela 1), sendo importante na interpretação do fluxo das águas subterrâneas e na quantificação das propriedades dos aquíferos. 
Tabela 1 - Síntese dos parâmetros hidrodinâmicos regionais do Sistema Aquífero Urucuia

Table 1 - Summary of regional hydrodynamic parameters of the Urucuia Aquifer System

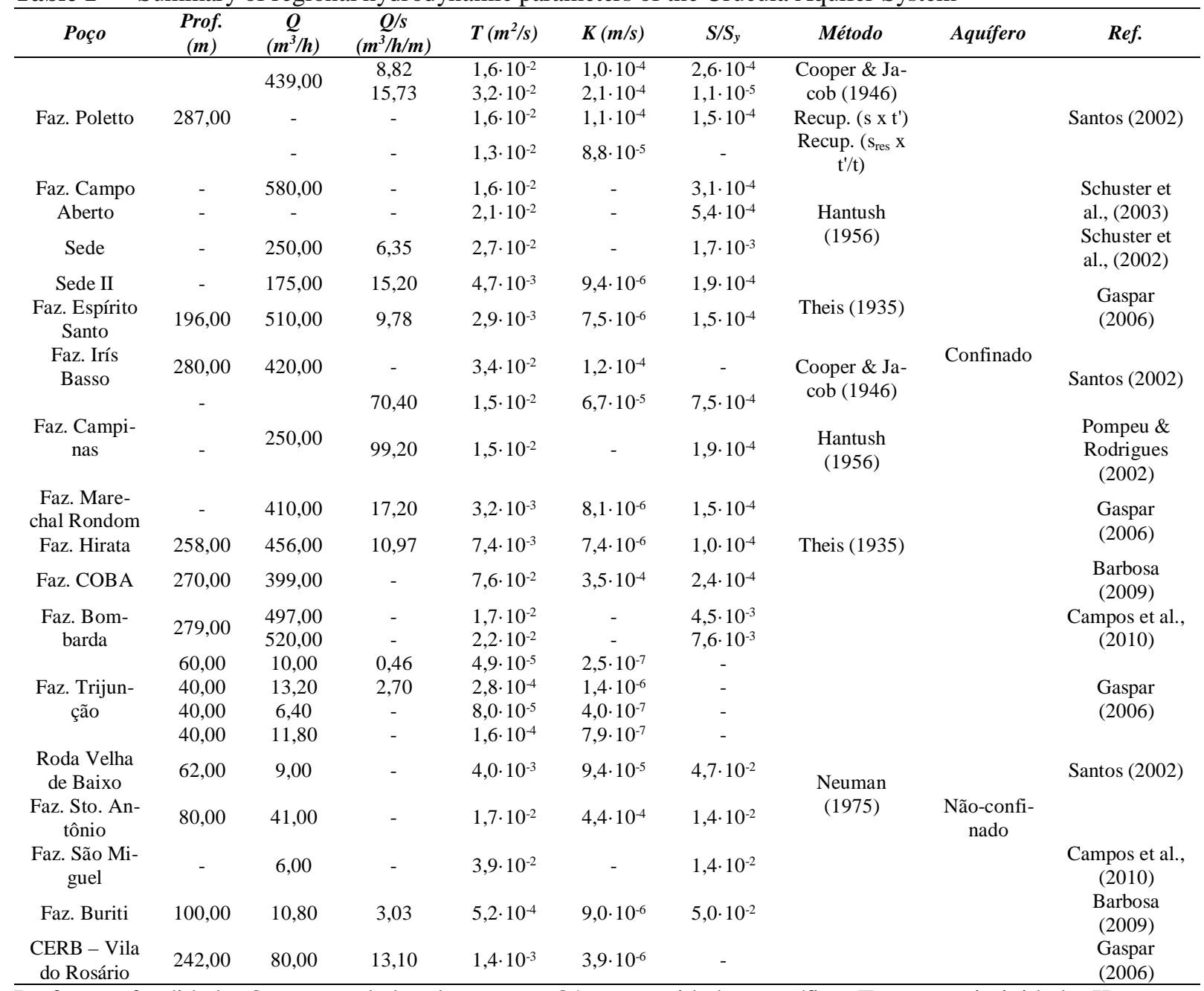

Prof. = profundidade; $\mathrm{Q}$ = vazão de bombeamento; $\mathrm{Q} / \mathrm{s}$ = capacidade específica; $\mathrm{T}$ = transmissividade; $\mathrm{K}=$ condutividade hidráulica; S = coeficiente de armazenamento; $S_{y}=$ porosidade efetiva; Ref = Referências.

\section{RESULTADOS E DISCUSSÕES}

Cinco perfis geofísicos foram interpretados, a saber: (i) Barreiras-Aeroporto, profundidade total de 169,30 m; (ii) BarreirasUniverso Verde Agronegócios Ltda, profundidade de 270,3 m; (iii) São Desidério-Perdizes, profundidade de 267,8 m; (iv) Luís Eduardo Magalhães-Sede (Poço 3), profundidade de 279,5 m e; (v) Correntina-Rosário, profundidade de 244,3 metros (Tabela 1; Figura 3).

\subsection{Perfil Barreiras-Aeroporto}

Localiza-se no extremo oriental da área (Figura 1). A interpretação geofísica (Fi- gura 2) mostra a presença de três eletrofácies (Figura 2). A inferior corresponde ao substrato regional composto de metassiltitos com metarcóseos intercalados e ardósias do Grupo Bambuí, representado por um aumento da argilosidade e do grau de compactação em profundidade (Figura 2-D, E). A intermediária, ou Formação Posse, é interpretada como depósitos de lençóis arenosos secos, constituídos por arenitos com laminação horizontal, correlacionável com os depósitos de campos de dunas situados no limite ocidental. Já a superior é constituída predominantemente por arenitos com laminações horizontais e conglomerados limitados por camadas maciças e silicificadas representada pela Formação Serra das Araras. 


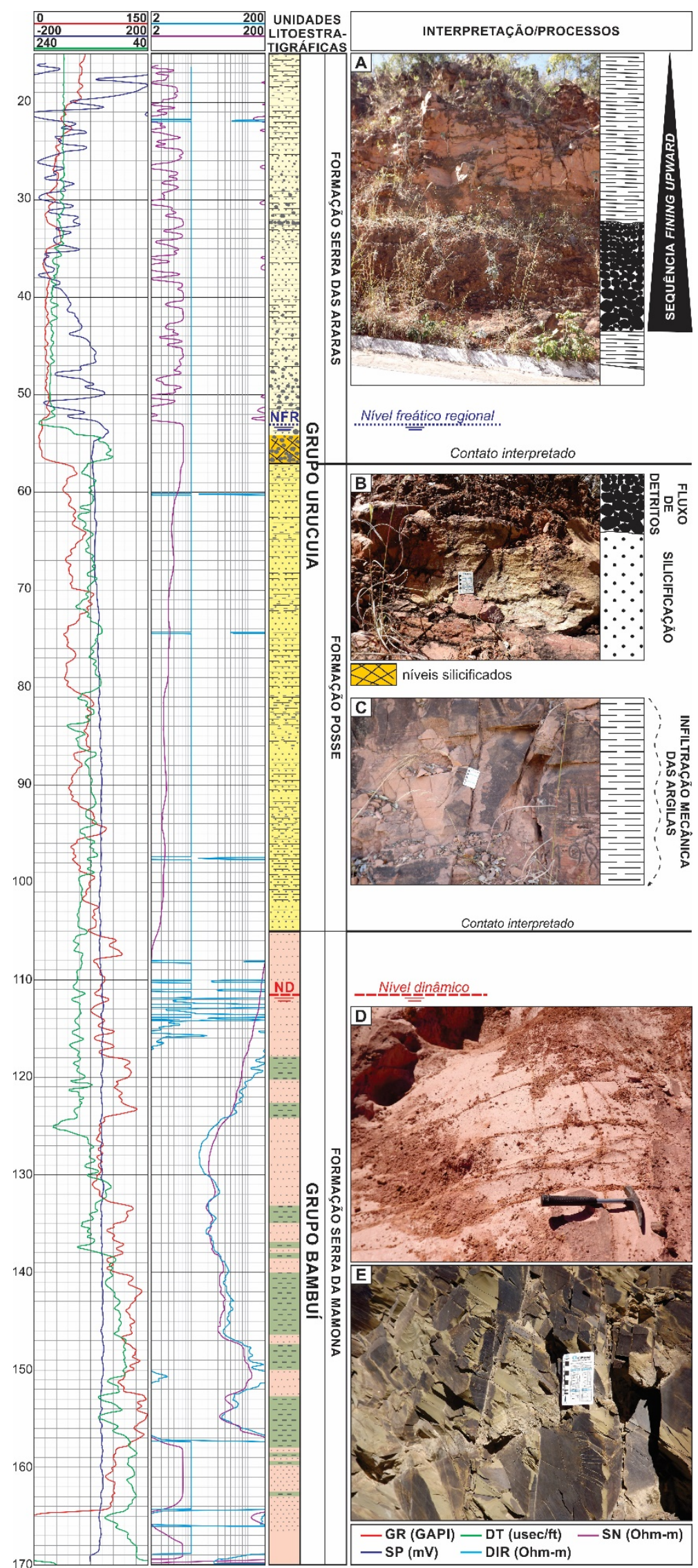

Figura 2 - Perfil geofísico do poço Barreiras-Aeroporto e interpretação hidrogeológica com fotografias das unidades estratigráficas aflorantes (A-E) na Serra da Bandeira (estrada de acesso ao aeroporto de Barreiras-BA)

Figure 2 - Barreiras-Aeroporto well log and hydrogeological interpretation with photos of outcropping stratigraphic units (A-E) in Bandeira Ridge (access road to Barreiras-BA airport) 
As camadas de arenitos silicificados e fraturados são restritas e apresentam uma deflexão acentuada no perfil DT, alcançando valores de 100 e $110 \mu \mathrm{seg} /$ pé. Já o nível freático é registrado pela variação abrupta do DT de $230 \mu \mathrm{seg} /$ pé a $180 \mu \mathrm{seg} /$ pé, na profundidade de $53,4 \mathrm{~m}$. O perfil GR, associado a investigações estratigráficas de campo, mostra arenitos com laminação horizontal interpretados como depósitos de lençóis arenosos (Figura 2-C) entre as profundidades de 57 a $105 \mathrm{~m}$. Nesse horizonte, é verificado um aumento da argilosidade, com dados GR entre 40 e 95 unidades API, interpretado como um processo diagenético de infiltração mecânica das argilas.

Em direção ao topo, têm-se ciclos de sedimentação fluvial com granodecrescência ascendente composto de conglomerados, arenitos com estratificações cruzadas de pequeno porte e laminações horizontais (Figura 2-A, B). Os níveis pelíticos são restritos. O contato inferido apresenta uma profundidade de 105 m para a superfície que limita os grupos Urucuia e Bambuí. Destaca-se que a unidade inferior do Grupo Urucuia, representada pela Formação Posse, se presente, mostra uma feição diferente das observadas nas porções ocidentais da bacia e descrita em trabalhos anteriores (CAMPOS e DARDENNE, 1997; CAMPOS e DARDENNE, 1999; SPIGOLON e ALVARENGA, 2002) (Figura 2-A, B, C, D). A presença restrita de depósitos de alta maturidade mineralógica e textural indica tratar-se da sedimentação transicional do sistema wadi fans do Grupo Urucuia.

\subsection{Perfil São Desidério-Perdizes}

Está localizado no distrito de Perdizes, a cerca de $30 \mathrm{~km}$ da sede municipal de São Desidério-BA (Figura 1). A interpretação geofísica mostra a presença de três eletrofácies (Figura 3). A inferior compõe o substrato regional representado pelo Grupo Bambuí, caracterizado por um aumento da argilosidade em profundidade. A intermediária e superior é caracterizada pelo Grupo Urucuia, subdivido nas formações Posse e Serra das Araras, com espessuras interpretadas de 72 m e 133 m, respectivamente. A intermediária apresenta uma maior argilosidade devido ao processo de infiltração mecânica de argilas nos arenitos. Já na superior, as camadas silicificadas dispõe-se na forma de níveis distribuídos em várias posições estratigráficas e apresenta como característica uma deflexão acentuada no perfil DT, alcançando valores acima de $110 \mu$ seg/pé. O nível freático interpretado é indicado pela variação abrupta do DT de $240 \mu$ seg/pé a 190 $\mu \mathrm{seg} / \mathrm{pé}$, na profundidade de $12,0 \mathrm{~m}$. Já o nível potenciométrico medido no poço ocorre na profundidade de 7,0 $\mathrm{m}$ (Tabela 2).

Tabela 2 - Dados hidrogeológicos dos poços perfilados Table 2 - Hydrogeological data of wells logs

\begin{tabular}{|c|c|c|c|c|c|c|c|}
\hline \multicolumn{2}{|c|}{ Poço } & \multirow{2}{*}{ Prof. (m) } & \multirow{2}{*}{$Q\left(m^{3} / h\right)$} & \multirow{2}{*}{$N E(m)$} & \multirow{2}{*}{$N D(m)$} & \multirow{2}{*}{$s(m)$} & \multirow{2}{*}{$Q / s\left(m^{3} / h / m\right)$} \\
\hline Município & Localidade & & & & & & \\
\hline Barreiras & Aeroporto & 169,30 & 5,73 & 52,00 & 111,67 & 59,67 & 0,10 \\
\hline São Desidério & Perdizes & 267,80 & 20,00 & 7,00 & 35,00 & 28,00 & 0,71 \\
\hline Barreiras & Universo Verde & 270,30 & 158,40 & 50,07 & 76,24 & 26,17 & 6,05 \\
\hline Luís Eduardo Magalhães & Sede & 279,50 & 175,70 & 19,14 & 30,71 & 11,57 & 15,19 \\
\hline Correntina & Rosário & 244,30 & 87,98 & 132,31 & 138,40 & 6,09 & 14,45 \\
\hline
\end{tabular}

Continuação:

\begin{tabular}{|c|c|c|c|c|c|c|}
\hline \multicolumn{2}{|c|}{ Poço } & \multirow{2}{*}{$h(m)$} & \multicolumn{3}{|c|}{ Parâmetros hidrodinâmicos } & \multirow{2}{*}{$\begin{array}{c}\text { Tipo de } \\
\text { aquífero }\end{array}$} \\
\hline Município & Localidade & & $T\left(m^{2} / s\right)$ & $S$ & Método & \\
\hline Barreiras & Aeroporto & 248,00 & $4,33 \times 10^{-6}$ & $2,80 \times 10^{-2}$ & Neuman & Não-confinado \\
\hline São Desidério & Perdizes & 293,00 & - & - & Hantush e Jacob & Confinado \\
\hline Barreiras & Universo Verde & 249,93 & $2,67 \times 10^{-4}$ & $1,70 \times 10^{-1}$ & Neuman & Não-confinado \\
\hline Luís Eduardo Magalhães & Sede & 280,86 & $3,17 \times 10^{-3}$ & $1,80 \times 10^{-4}$ & Hantush e Jacob & Confinado \\
\hline Correntina & Rosário & 167,69 & $1,90 \times 10^{-6}$ & $2,50 \times 10^{-2}$ & Neuman & Não-confinado \\
\hline
\end{tabular}

Prof. = profundidade; $\mathrm{Q}$ = vazão de bombeamento; NE = nível estático; ND = nível dinâmico; s = rebaixamento; $\mathrm{Q} / \mathrm{s}$ = capacidade específica; $\mathrm{h}$ = carga hidráulica; $\mathrm{T}$ = transmissividade; $\mathrm{S}$ = coeficiente de armazenamento. 

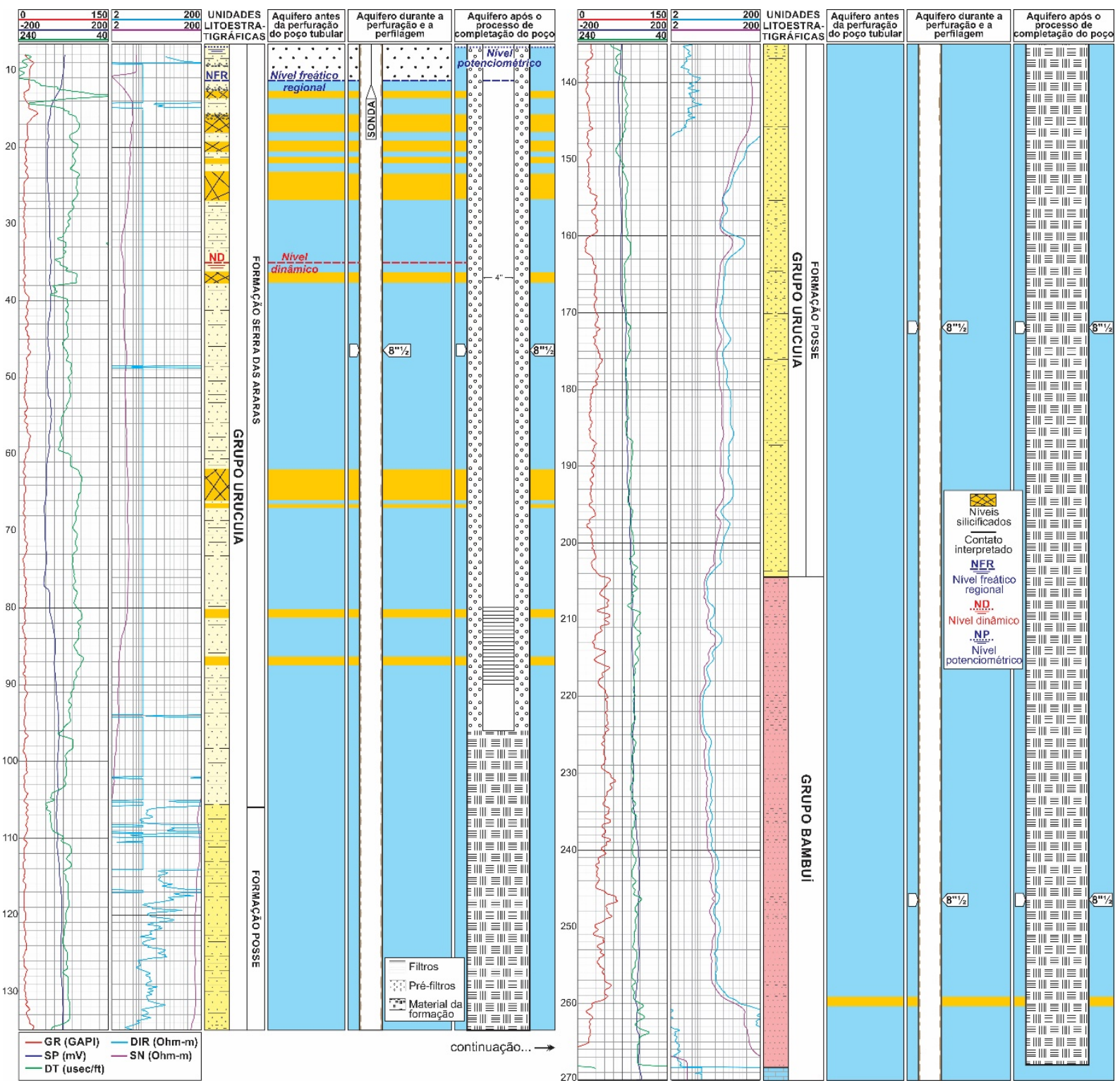

Figura 3 - Perfil geofísico do poço São Desidério-Perdizes ilustrando o comportamento hidrogeológico do sistema aquífero antes da perfuração, durante a operação de perfilagem e após a completação e desenvolvimento do poço (modificado de Nascimento, 2003).

Figure 3 - São Desidério-Perdizes well log illustrating hydrogeological behavior of the aquifer system before drilling, during the logging operation and after the completion and well development (modified from Nascimento, 2003).

\subsection{Perfil Barreiras-Universo Verde Agro- negócios}

Situa-se a aproximadamente $40 \mathrm{~km}$ a oeste do poço Barreiras-Aeroporto (Figura 1). Apresenta duas eletrofácies, constituídas por arenitos e níveis silicificados intercalados em várias posições estratigráficas, representados pelas formações Posse e Serra das Araras (Figura 4). O nível freático é registrado pela variação abrupta do DT de $240 \mu \mathrm{seg} /$ pé a 80 $\mu \mathrm{seg} / \mathrm{pé}$, na profundidade de $50,0 \mathrm{~m}$. A unida- dade superior, ou Formação Serra das Araras, é caracterizada por um padrão serrilhado no perfil DT, com os maiores valores, de 80 a 130 $\mu \mathrm{seg} /$ pé, interpretado como níveis de arenitos silicificados. O contato com a unidade inferior, representado pela Formação Posse é revelado por modificações no padrão do perfil DT na profundidade de $114 \mathrm{~m}$. Em geral, ambas as formações possuem um padrão GR uni forme, representando pacotes arenosos limpos. 
BARBOSA, N.S.; LEAL, L.R.B ; MELLO, J.C. ; PEIXINHO, M.A.L.; SANTOS, C.B. ; SANTOS, R.L.S. ; BARBOSA, N.S.

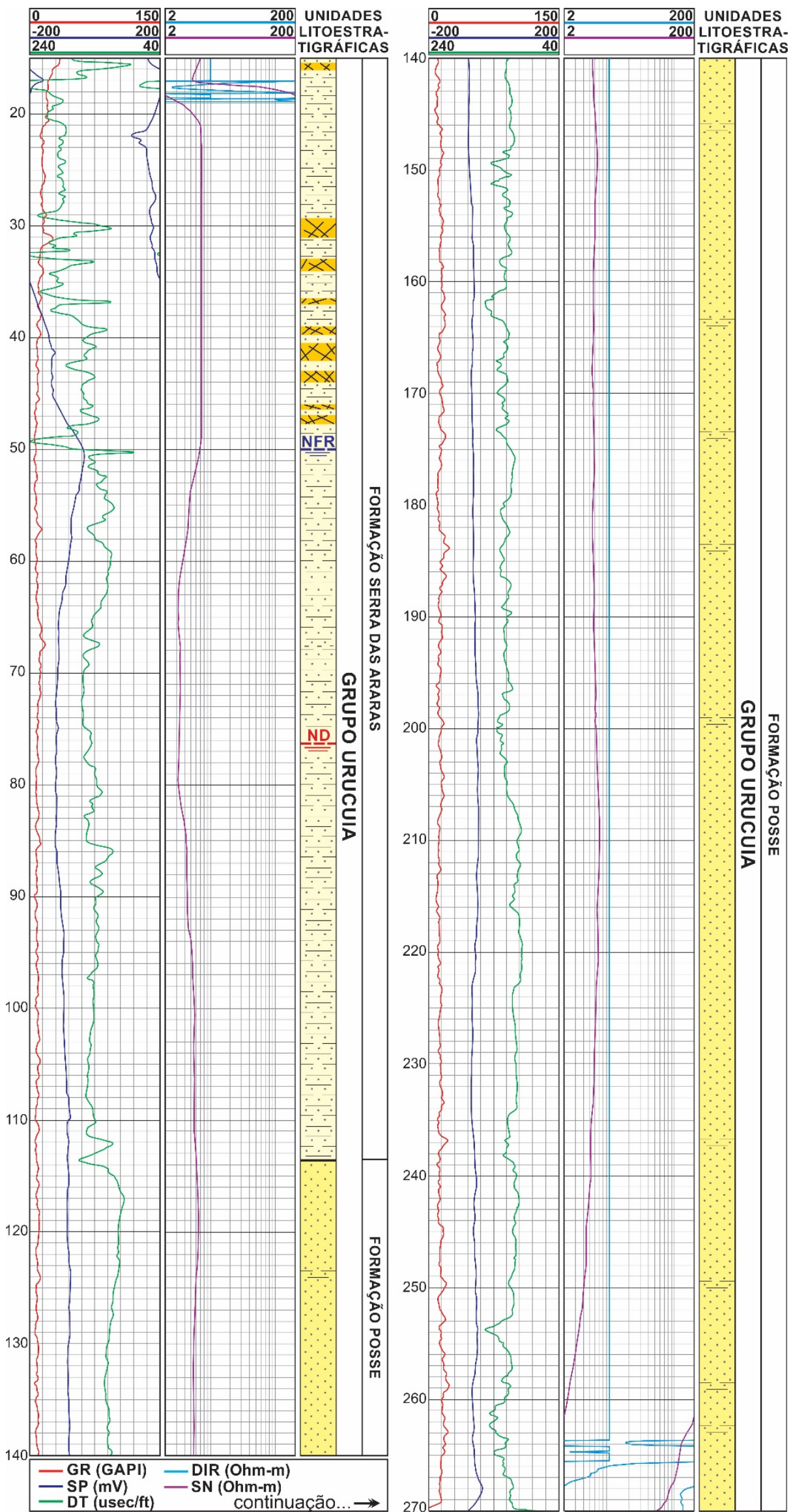

Figura 4 - Interpretação hidrogeológica do perfil geofísico do poço Barreiras-Universo Verde Agreonegócios

Figure 4 - Hydrogeological interpretation of Barreiras- Universo Verde Agronegócios well log 


\subsection{Perfil Luís Eduardo Magalhães-Sede Ii (Poço 3)}

Localiza-se na porção central da área, na sede do município de Luís Eduardo Magalhães-BA (Figura 1). A interpretação, ilustrada na Figura 5, mostra a presença de duas eletrofácies. A superior, representada pela Formação Serra das Araras, constituída predominantemente por arenitos limitados por espessas camadas de arenitos silicificados. Esses últimos apresentam uma deflexão acentuada no perfil DT, alcançando va

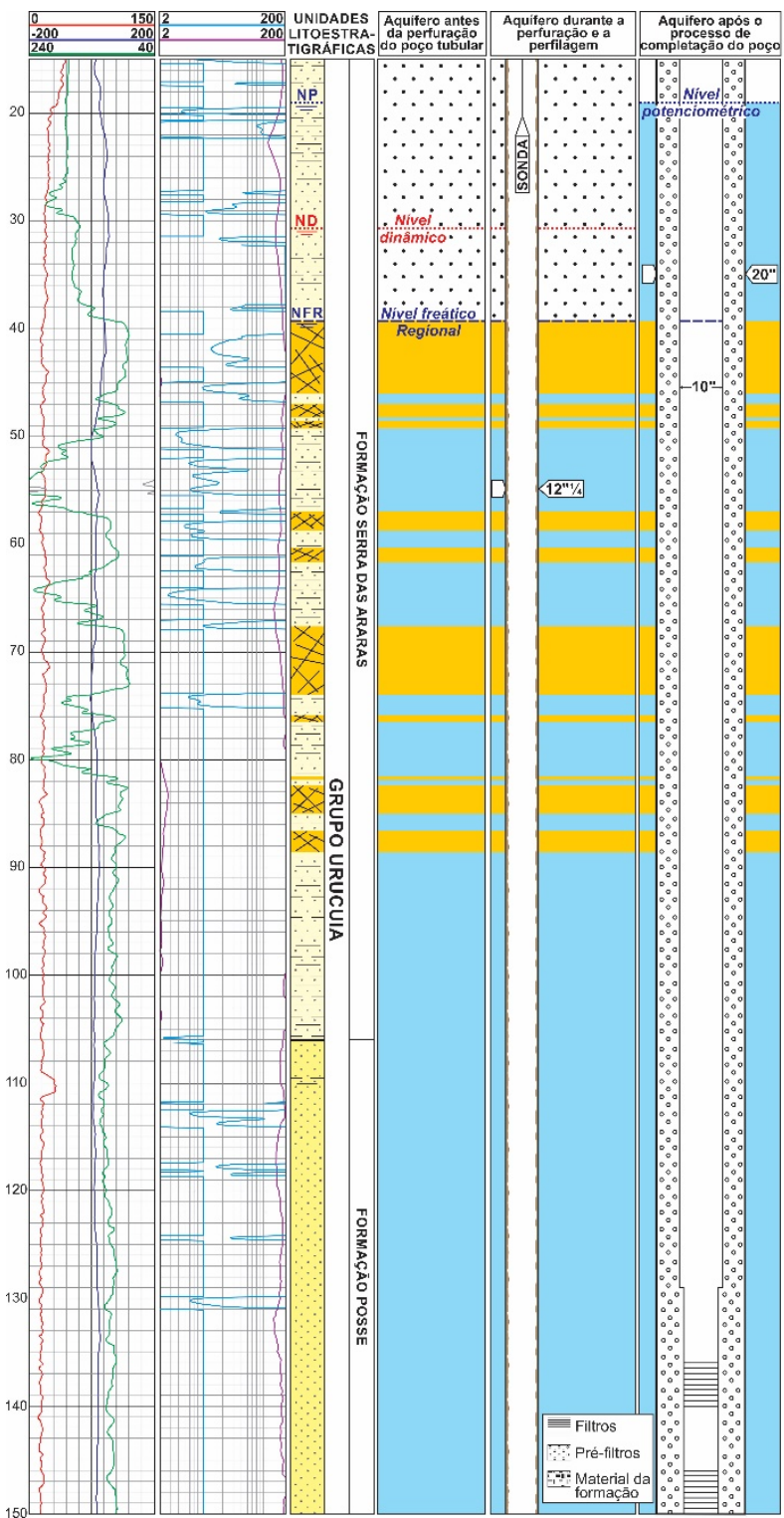

lores de 85 a $100 \mu$ seg/pé. Já o nível freático é registrado pela variação abrupta do DT de $150 \mu \mathrm{seg} /$ pé a $85 \mu \mathrm{seg} /$ pé, na profundidade de $38,7 \mathrm{~m}$. Enquanto que o nível potenciométrico, medido no poço, ocorre na profundidade de 7,0 m (Tabela 2). A unidade relacionada à Formação Posse apresenta uma maior uniformidade nos sedimentos, caracterizado por um padrão regular no perfil DT e GR. O contato inferido entre as unidades é de $106 \mathrm{~m}$, marcado por modificações no padrão do perfil DT, de serrilhado a regular, respectivamente.

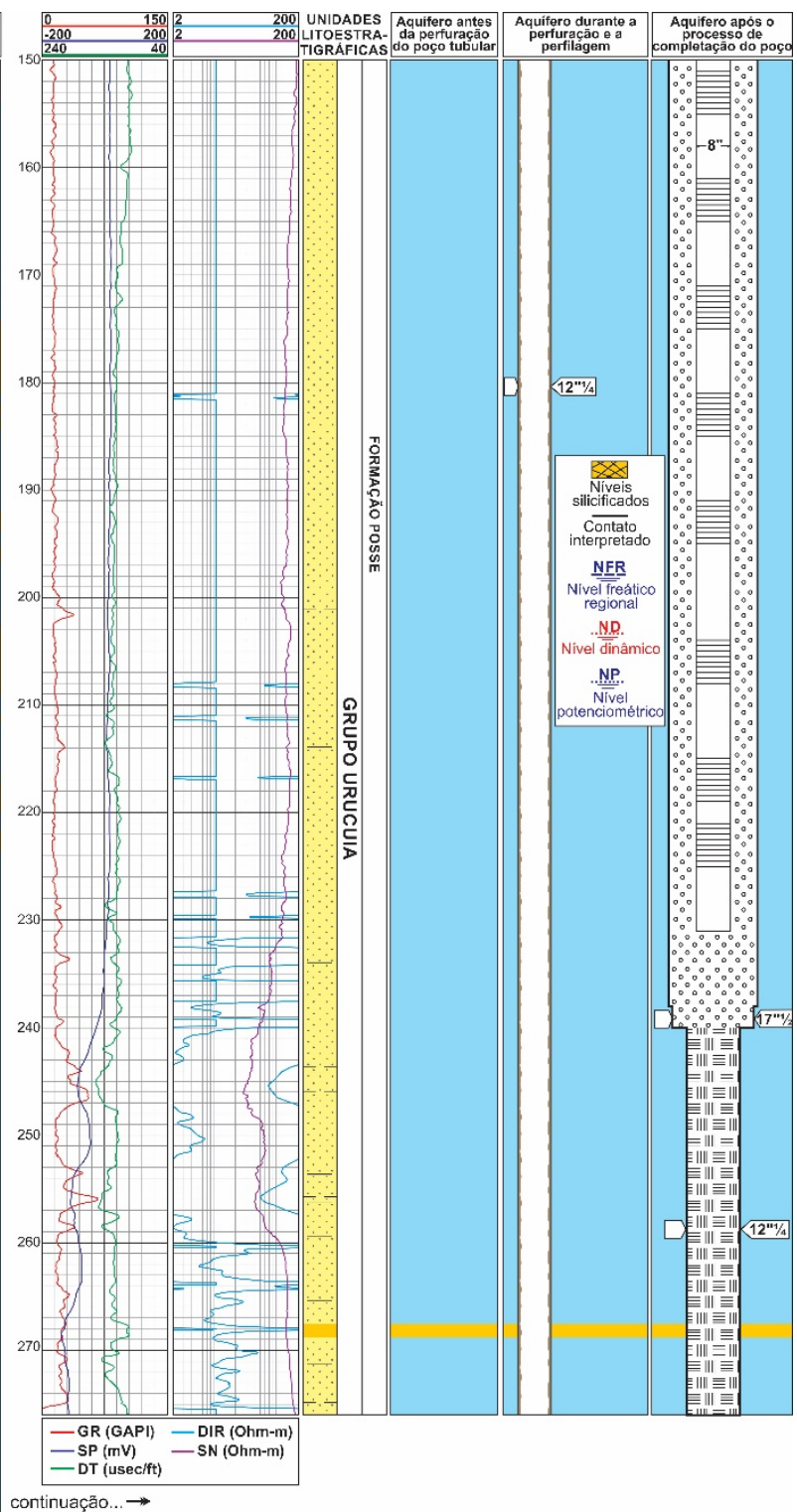

Figura 5 - Perfil geofísico do poço Luís Eduardo Magalhães-Sede (Poço 3) mostrando o comportamento hidrogeológico do sistema aquífero antes da perfuração, durante a operação de perfilagem e após a completação e desenvolvimento do poço

Figure 5 - Luís Eduardo Magalhaes-Sede (Well 3) well log showing the hydrogeological behavior of the aquifer system before drilling, during the logging operation and after completion and well development 


\subsection{Perfil Correntina-Rosário}

Está situado no extremo ocidental da área, no distrito de Rosário, município de Correntina-BA (Figura 1). A interpretação (Figura 6A-F), revela a presença de duas eletrofácies. A unidade superior, representada pela Formação Serra das Araras, é constituída de padrões DT serrilhados com níveis restritos de arenitos silicificados e caracterizados por valores DT entre 60 e $80 \mu \mathrm{seg} /$ pé. A presença desses níveis na zona de aeração possibilitou a identificação de um aquífero suspenso. Já aqueles desenvolvidos na unidade inferior, ou Formação Posse, dispõem-se de forma regular. O nível freático é indicado pela variação abrupta do DT de $135 \mu \mathrm{seg} /$ pé a $110 \mu \mathrm{seg} /$ pé, na profundidade de $136 \mathrm{~m}$. O contato inferido entre as unidades geológicas é de $135 \mathrm{~m}$, marcado por modificações no padrão do perfil DT. Representa a sedimentação distal do Grupo Urucuia, expressa por litofácies de arenitos com estratificações cruzadas de grande porte em escala métrica limitadas por estratificações horizontais e de baixo ângulo, o qual corresponde em conjunto a sucessões de dunas e interdunas (Figura 6-D). O contato entre as unidades marca o início de períodos mais úmidos, sendo constituídos por depósitos de fluxo de detritos arenosos (Figura 6-D), separando o sistema eólico (Formação Posse) do sistema fluvial-eólico (Formação Serra das Araras) (Figura 6-A, B, C).

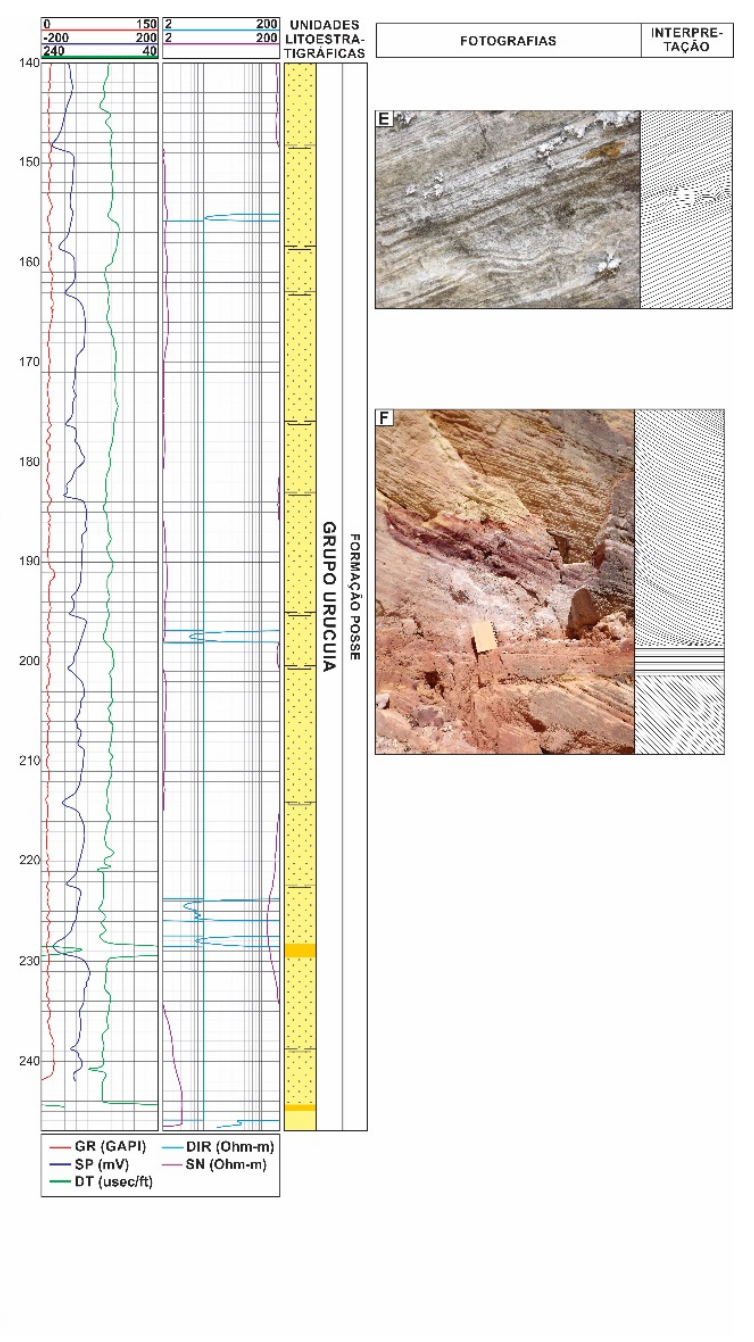

Figura 6 - Perfil geofísico do poço Correntina-Rosário e interpretação hidrogeológica com as fotografias das unidades estratigráficas aflorantes (A-F) na Serra da Geral de Goiás (rodovia GO-362 de acesso à cidade de São Domingos-GO)

Figure 6 - Correntina-Rosário well log and hidrogeological interpretation with photographs of the outcropping stratigraphic units (A-F) in the Serra Geral de Goiás (GO-362 highway to the city of São Domingos-GO) 


\subsection{Modelo hidrogeológico conceitual}

A interpretação dos perfis geofísicos possibilitou a caracterização das unidades litoestratigráficas, dos contatos litológicos inferidos e da hidrogeologia do SAU Centro-Ocidental. A Figura 7 ilustra um modelo hidrogeológico conceitual idealizado após a integração dos perfis geofísicos e demonstra que o SAU apresenta modificações no seu comportamento hidrogeológico/hidrodinâmico a depender da sua posição na bacia. Nela, as espessuras sedimentares e saturadas aumentam progressivamente em direção às porções ocidentais, exceto no extremo ocidental, onde ocorre um divisor na bacia hidrogeológica. Já as espessuras dos níveis de arenitos silicificados aumentam em direção à porção central. Nesse pacote sedimentar, a presença e posição estratigráfica dos níveis de arenitos silicificados e a relação desses com a posição do nível freático regional condicionam o comportamento hidrogeológico do SAU, em um sistema tipo aquífero-aquitarde-aquífero (BARBOSA et al., 2014) (Figura 8). Esse sistema é representado por um aquífero superior do tipo livre, níveis de arenitos silicificados e fraturados caracterizados como uma unidade de confinamento e um aquífero inferior do tipo confinado.

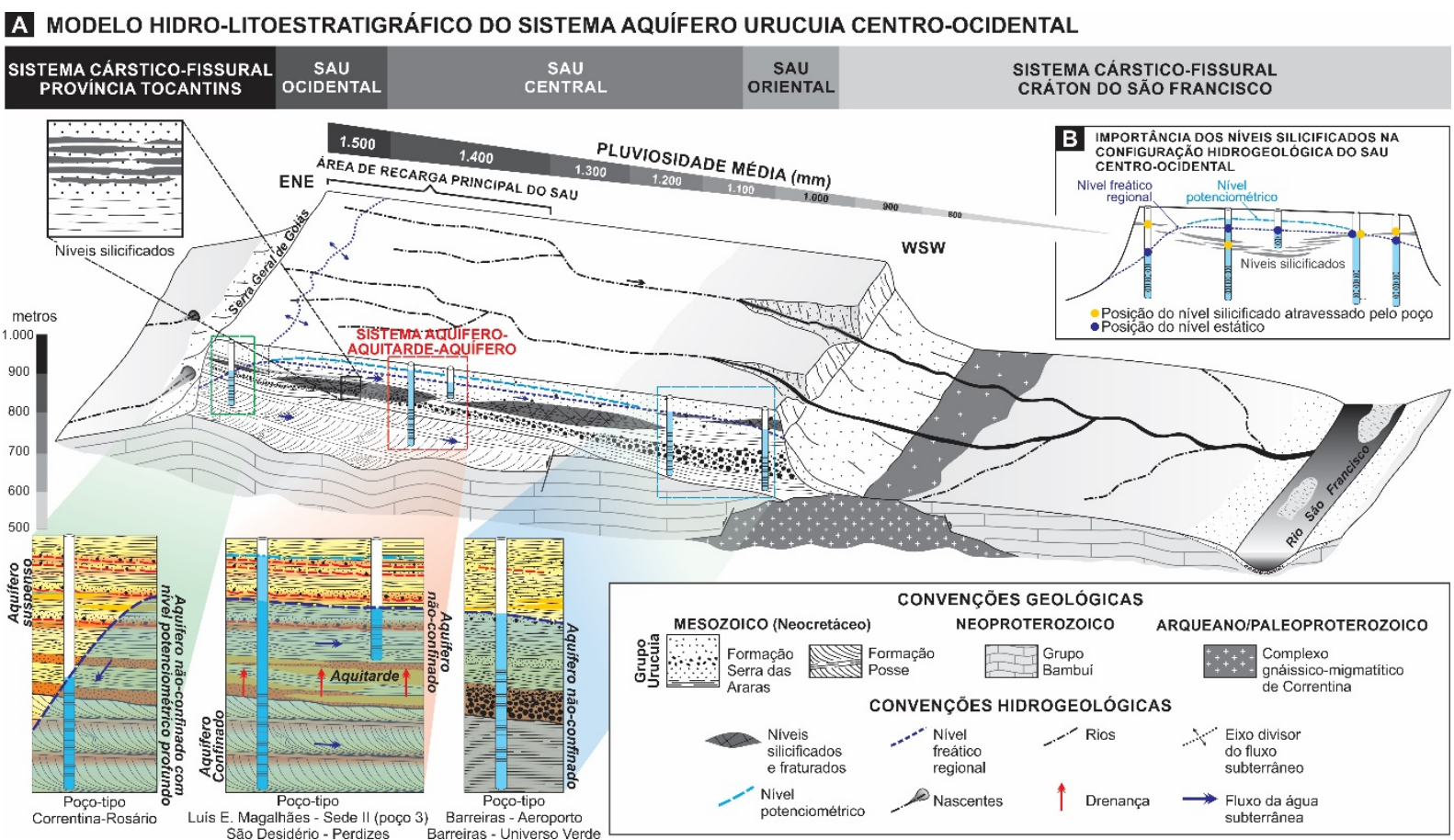

Figura 7 - Modelo hidrogeológico conceitual do Sistema Aquífero Urucuia, com base na interpretação dos perfis geofísicos (A), enfatizando a importância dos níveis silicificados na configuração hidrogeológico (B) (modificado de Barbosa et al., 2014)

Figure 7 - Conceptual hydrogeologic model for the Urucuia Aquifer System, based on the interpretation of geophysical logs (A), emphasizing the importance of silicified levels hydrogeological behavior (B) (modificado from Barbosa et al., 2014)

Em síntese, quando os níveis de arenitos silicificados posicionam-se acima do nível freático regional o aquífero têm um comportamento não-confinado, conforme verificado nos perfis Barreiras-Aeroporto, BarreirasUniverso Verde (Figuras 2 e 4). Consiste em um aquífero onipresente na área estudada e, por vezes, sobrepõe-se às demais unidades aquíferas. Possui transmissividade variável, com valores de $4,33 \cdot 10^{-6}$ a $2,67 \cdot 10^{-4} \mathrm{~m}^{2} / \mathrm{s}$. Já as porosidades efetivas são elevadas, com valores de $2,82 \cdot 10^{-2}$ e $1,70 \cdot 10^{-} 1$, respectivamente (Tabela 2). Comumente é explotado para o abastecimento das sedes das fazendas e na diluição de agrotóxicos nas lavouras (GASPAR e CAMPOS, 2007). 
BARBOSA, N.S.; LEAL, L.R.B ; MELLO, J.C. ; PEIXINHO, M.A.L.; SANTOS, C.B. ; SANTOS, R.L.S. ; BARBOSA, N.S.

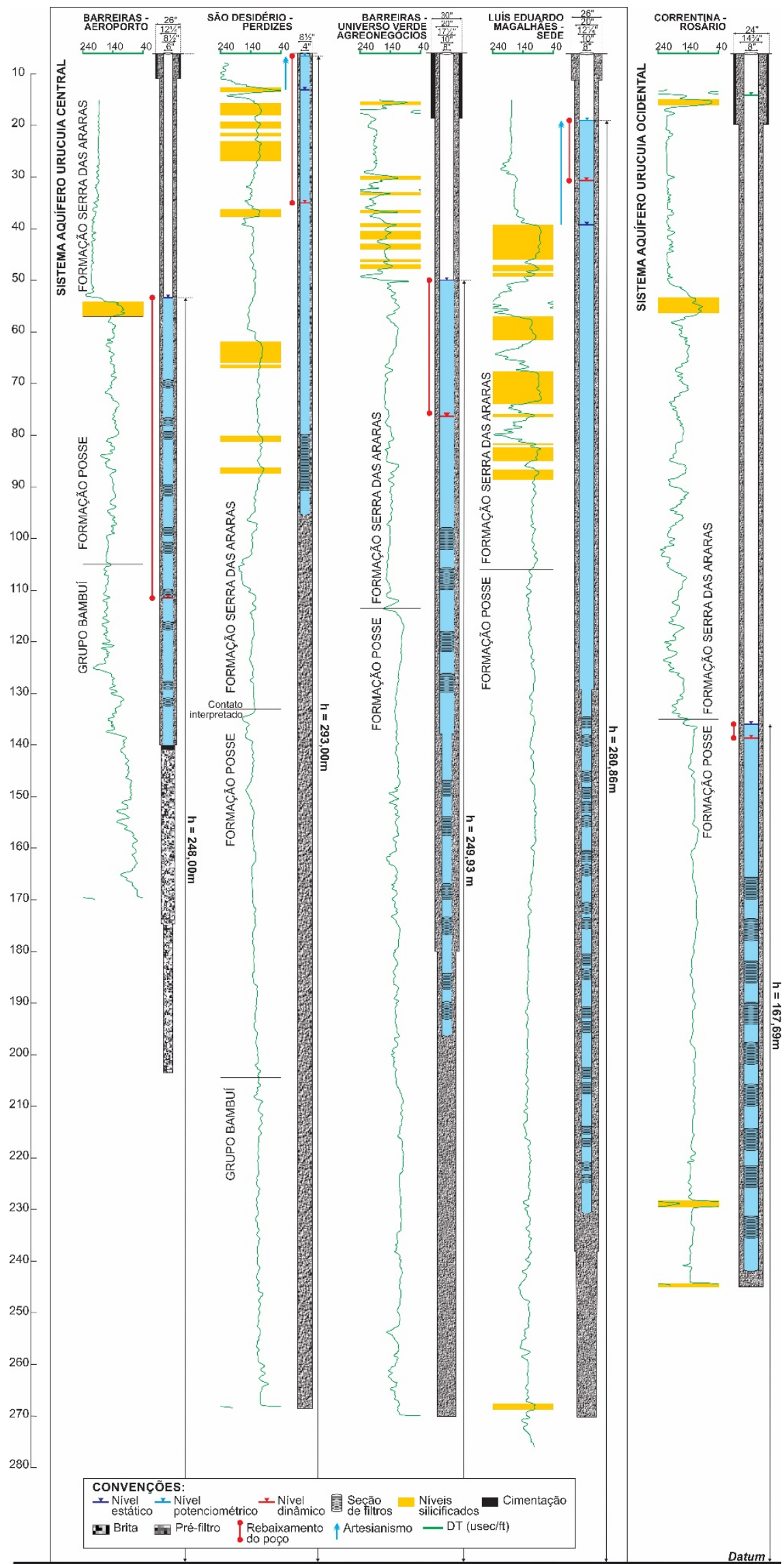

Figura 8 - Correlação hidrogeológica dos poços perfilados destacando o perfil construtivo e as cargas hidráulicas totais

Figure 8 - Hydrogeological correlation of wells logs highlighting the constructive profile and total hydraulic heads 
No perfil Correntina-Rosário, o aquífero não-confinado possui nível freático profundo (i.e., 132,32 m). Nesse subtipo, têm-se um aumento progressivo da superfície potenciométrica em profundidade, responsável pela presença de um eixo de inflexão do fluxo subterrâneo de direção aproximada N-S, caracterizado por menores valores de carga hidráulica (i.e., 167,69 m) e pela recarga do Sistema Cárstico-Fissural subjacente (Tabela 2; Figura 2). Nesse perfil, a presença de níveis de arenitos silicificados na zona de aeração possibilita a ocorrência de aquíferos suspensos de distribuição local (Figuras 6 e 7). Compreende o SAU Ocidental e apresenta valores de transmissividade da ordem de $1,90 \cdot 10^{-6} \mathrm{~m}^{2} / \mathrm{s}$ e porosidade efetiva de $2,50 \cdot 10^{-2}$. Os valores dos coeficientes de transmissividade observados nos poços que atravessam os aquíferos não confinados (i.e., Barreiras-Aeroporto, Barreiras-Universo Verde e Correntina-Rosário) tendem a diminuir em direção às regiões extremo ocidental e oriental que limitam a bacia hidrogeológica, em função principalmente da redução da espessura saturada (Figura 7).

Já quando os níveis de arenitos silicificados posicionam-se abaixo do nível freático regional, o aquífero se apresenta como um sistema aquífero-aquitarde-aquífero (BARBOSA et al., 2014). Nessa configuração, os níveis de arenitos silicificados dispõe-se fraturados e representam uma unidade de confinamento do SAU, conforme verificado nos perfis de Luís Eduardo Magalhães-Sede (poço 3) e São Desidério-Perdizes. Neles, o nível freático interpretado foi de aproximadamente 39,0 e 12,0 m, enquanto que o nível potenciométrico medido nos poços apresentaram 19,14 e 7,0 m de profundidade, respectivamente. Em geral, exibem cargas hidráulicas maiores (i.e., 280,86 e 293,00 m) em relação ao aquífero não confinado sobrejacente (i.e., 248,00 e 249,93 m) (Tabela 2; Figura 8). A diferença nos valores das cargas hidráulicas verificadas nos poços pode, provavelmente, ser relacionada a existência de uma drenança vertical entre os aquíferos sobrepostos. Em geral, possui alta transmissividade, com valores da ordem de $3,17 \cdot 10^{-3} \mathrm{~m}^{2} / \mathrm{s}$, e coeficiente de armazenamento, da ordem de $1,81 \cdot 10^{-4}$ (Tabela 2). Co- mumente é explotado por intermédio de poços tubulares profundos utilizados em projetos de irrigação em pivôs centrais.

As magnitudes dos rebaixamentos produzidos nos poços, após os ensaios de bombeamento, diminuem progressivamente no sentido da porção centro-ocidental, com valores de 59,$67 ; 28,00 ; 26,17 ; 11,57$ e 6,09 , respectivamente, associado a uma tendência de aumento na vazão de explotação e na potencialidade hídrica dos poços, fato corroborado pelos valores de capacidades específicas de 14,$4 ; 15,2 ; 6,1 ; 0,71$ e $0,1 \mathrm{~m}^{3} / \mathrm{h} / \mathrm{m}$ para os poços Correntina-Rosário, Luís Eduardo Maglhães-Sede (Poço 3), Barreiras-Universo Verde Agronegócios, São Desidério-Perdizes e Barreiras-Aeroporto, respectivamente (Tabela 2, Figura 8).

\section{CONSIDERAÇÕES FINAIS}

Os resultados da interpretação de perfis geofísicos e ensaios de bombeamento dos poços demonstram que o SAU apresenta diferentes comportamentos hidrogeológicos em função da presença de níveis de arenitos silicificados, das variações dos parâmetros hidrodinâmicos das unidades aquíferas e do posicionamento geomorfológico e geográfico na sua área de abrangência.

As características dos diferentes subtipos aquíferos são modificadas de acordo com a posição estratigráfica dos níveis de arenitos silicificados em relação às do nível freático regional. No subtipo não-confinado, os níveis de arenitos silicificados estão posicionados acima do nível freático, conforme verificado nos poços Barreiras-Aeroporto, BarreirasUniverso Verde Agronegócios e CorrentinaRosário. Esse último, localizado no extremo ocidental, possui nível estático profundo, fruto de um divisor de água subterrânea na bacia hidrogeológica. Adicionalmente possuem porosidades efetivas elevadas (i.e., entre $10^{-2}$ a $10^{-1}$ ) e valores variáveis de transmissividade (i.e., da ordem de $10^{-4}$ a $10^{-6} \mathrm{~m}^{2} / \mathrm{s}$ ), com os menores valores observados nos extremos limítrofes da área estudada devido provavelmente à diminuição da espessura saturada.

Já no subtipo confinado, os níveis es- 
pessos de arenitos silicificados posicionam-se abaixo do nível freático e compõem um sistema aquífero-aquitarde-aquífero, a exemplo dos poços São Desidério-Perdizes e Luís Eduardo Magalhães-Sede (poço 3). Neles, ocorre uma elevação do nível d’água (i.e., artesianismo) de aproximadamente 5,0 e 20,0 m, respectivamente. Complementarmente, possui alta transmissividade (da ordem de $10^{-3} \mathrm{~m}^{2} / \mathrm{s}$ ) e baixo coeficiente de armazenamento (em torno de $10^{-4}$ ). Em geral, apresenta cargas hidráulicas maiores do que as verificadas no subtipo livre sobrejacente. Destaca-se que, apesar desse tipo de aquífero ocorrer em situações e posições espaciais específicas na bacia (e.g., SAU Centro-Ocidental), a distribuição espacial e estratigráfica dos níveis de arenitos silicificados ainda não estão regionalmente caracterizados. Via de regra, a magnitude dos rebaixamentos produzidos nos ensaios de bombeamento dos poços, diminuem progressivamente em direção à porção centro-ocidental do SAU, aliado a um aumento da capacidade específica dos poços, da espessura saturada e da potencialidade hidrogeológica.

No modelo proposto, a configuração dos diferentes subtipos aquíferos ocorre em função das variações litológicas, da estrutura hidrogeológica e dos parâmetros hidrodinâmicos do SAU. Em síntese, esse sistema é representado por um aquífero superior do tipo livre e onipresente na área de estudo, níveis de arenitos silicificados e fraturados caracterizados como uma unidade de confinamento e um aquífero inferior do tipo confinado. Na interpretação dos perfis, a disposição em profundidade da unidade de confinamento nem sempre corresponde ao limite das unidades litoestratigráficas formais.

\section{AGRADECIMENTOS}

Os autores agradecem à CERB (Companhia de Engenharia Hídrica e Saneamento da Bahia) e a HIDROLOG Serviços de Perfilagem pela disponibilização e autorização de uso dos perfis geofísicos de poços.

\section{REFERÊNCIAS}

AMORIM JUNIOR, V. Avaliação hidrogeológica do aquífero Urucuia na bacia do rio das Fêmeas usando IP-Resistividade. Salvador, Bahia, 2003. 82p. Dissertação de Mestrado. Instituto de Geociências da Universidade Federal da Bahia.

AMORIM JUNIOR, V.; LIMA, O.A.L. Avaliação hidrogeológica do Aquífero Urucuia na bacia do rio das Fêmeas usando resistividade e polarização elétrica induzida. Revista Brasileira de Geofísica. 25 (2): 117-129, 2007.

BARBOSA, N.S. Avaliação dos Parâmetros Hidrodinâmicos do Aquífero Urucuia nas Bacias Hidrográficas dos Rios Formoso e Arrojado Oeste do Estado da Bahia. Salvador, Bahia, 2007. 119 p. Trabalho de Conclusão de Curso. Instituto de Geociências da Universidade Federal da Bahia.

BARBOSA, N.S. Hidrogeologia do Sistema Aquífero Urucuia nas bacias hidrográficas dos rios Formoso e Arrojado. Salvador, Bahia, 2009. 98p. Dissertação de mestrado. Instituto de Geociências-Universidade Federal da Bahia.

BARBOSA, N.S.; LEAL, L.R.B.; BARBOSA, N.S.; MELLO, J.C.; SANTOS, C.B. Os Diferentes Comportamentos Hidrogeológicos do Sistema Aquífero Urucuia na Região Oeste do Estado da Bahia. In. CONG. BRAS. GEOL, 45, Anais..., CD-ROM. Belém-PA. 2010.

BARBOSA, N.S.; GUIMARÃES, R.P.; NASCIMENTO, D.S.; BARBOSA, N.S. Geoarquitetura deposicional e correlação estratigráfica dos arenitos eólicos do Grupo Urucuia, Oeste da Bahia e Nordeste de Goiás. In: XXIV SIMPÓSIO DE GEOLOGIA DO NORDESTE, 2011, Anais..., Aracajú-SE, 2011. p. 260.

BARBOSA, N.S.; LEAL, L.R.B.; BARBOSA, N.S.; MELLO, J.C.; SANTOS, C.B; LIMA, O.A.L. Caracterização Geométrica e Hidráulica do Sistema Aquífero Urucuia Meridional com base em Testes de Bombeamento e Levantamentos Geofísicos Elétricos. Revista Águas Subterrâneas. 28 (2): 41-52, 2014.

BONFIM, L.F.C.; GOMES, R.A.A.D. Aqüífero Urucuia - Geometria e Espessura: Idéias para Discussão. In: CONGRESSO BRASILEIRO DE 
ÁGUAS SUBTERRÂNEAS, XX, Cuiabá (MT), Anais... 1 CD-ROM. 2004. 8 pp.

BORGES, M.S.; IGREJA, H.L.S.; COSTA, J.B.S.; HASUI, Y. Faciologia e Tectônica da Formação Urucuia na Região de Dianópolis, Sudeste do Estado do Tocantins. Geociências, São Paulo, 11(1): 7-18. 1992.

CAMPOS, J.C.V.; BRIZ, E.M.; LUZ, J.A.G. Determinação dos Parâmetros Hidrodinâmicos do Aquífero Urucuia - Fazenda Bombarda. In: CONGRESSO BRASILEIRO DE ÁGUAS SUBTERRÂNEAS, XVI, São Luís (MA), Anais..., 2010, p.1-17.

CAMPOS, J.E.G.; DARDENNE, M.A. A carta estratigráfica da bacia Sanfranciscana. In: CONGRESSO BRASILEIRO DE GEOLOGIA, 38, Balneário Camboriú (SC), Anais..., 1994, p.5051.

CAMPOS, J.E.G.; DARDENNE, M.A. Estratigrafia e sedimentação da bacia Sanfranciscana: uma revisão. Revista Brasileira de Geociências, 27: 269-282. 1997.

CAMPOS, J.E.G.; DARDENNE, M.A. Distribuição, estratigrafia e sistemas deposicionais do Grupo Urucuia - Cretáceo Superior da Bacia Sanfranciscana. Geociências, São Paulo, 18(2): 481499. 1999.

GASPAR, M.T.P. Sistema Aqüífero Urucuia: Caracterização Regional e Propostas de Gestão. Brasília-DF. 2006. 158 p. Tese de doutorado $\mathrm{n}^{\circ}$ 76. IG-UnB.

GASPAR, M.T.P.; CAMPOS, J.E.G. O Sistema Aquífero Urucuia. Revista Brasileira de Geociências, 37(4): 216-226, 2007.

GASPAR, M.T.P.; CAMPOS, J.E.G.; MORAES, R.A.V de. Determinação das espessuras do Sistema Aquífero Urucuia a partir de estudo geofísico. Revista Brasileira de Geociências, 42 (Suppl 1): 154-166. 2012.

HANTUSH, M.S.; JACOB, C.E. Non-steady radial flow in an infinite leaky aquifer. Trans. Amer. Geophys. Union. 36: 95-100. 1955.

KIANG, C.H; SILVA, F.P. Contribuição ao arcabouço geológico do Sistema Aquífero Urucuia. Geociências, 34(4): 872-882. 2015.
LIMA, O.A.L. Estudos geológicos e geofísicos do Aquífero Urucuia na Bacia do Rio Cachorro Oeste do Estado da Bahia. Relatório técnico. Salvador-BA. 2000. Superintendência de Recursos Hídricos- SRH/ Centro de Pesquisas em Geofísica e Geologia-CPGG/UFBA. 42p.

LIMA, O.A.L; SANTOS, E.S.M. Caracterização geológica e geofísica do Sistema Aquífero Urucuia e de seu substrato nas bacias dos rios Arrojado e Formoso, Bahia. Revista Brasileira de Geofísica. 29(4): 723-744. 2011.

LUZ, J.A.G.; COSTA, A.T.; CAMPOS, J.C.V. Avaliação sobre as condições atuais de explotação dos poços e dinâmica de fluxo do aquífero Urucuia. Relatório Final. Barreiras-BA. 2009. Universidade Federal da Bahia - UFBA. 89p.

MARTINS, L.A; CARDOSO, A.C. O Aquífero Urucuia no Estado de Minas Gerais. In: CONGRESSO BRASILEIRO DE ÁGUAS SUBTERRÂNEAS, XVII, 2012, Bonito-MS, Anais..., 4 pp.

NASCIMENTO, K.R.F. (coord.). Uso conjunto das águas superficiais e subterrâneas da Sub-Bacia do Rio das Fêmeas- Bahia. Relatório Final. Salvador- BA. 2003. ANA/ GEF/ PNUMA/ OEA, Superintendência de Recursos Hídricos (SRH). 208 pp.

NERY, G.G.; BARROS, S.B.R. O uso dos perfis geofísicos na definição de ambientes deposicionais. In: 1ST JOINT WORLD CONGRESS ON GROUNDWATER. 2000, Fortaleza (CE), Anais..., 16 pp.

NEUMAN, S.P. Analysis of pumping test data from anisotropic unconfined aquifers considering delayed gravity response. Water Resources Res. 11: 329-342. 1975.

OLIVEIRA, L.T.; LUZ, J.A.G.; CAMPOS, J.C.V.; LIMA, O.A.; LEAL, L.R.B. Comportamento hidrogeológico do Grupo Urucuia: Sub-bacia dos rios Formoso e Arrojado. In: CONGRESSO BRASILEIRO DE ÁGUAS SUBTERRÂNEAS, 15. Natal (RN), 2008, Anais..., p.1-15.

PIMENTEL, A.L.; AQUINO, R.F.; SILVA, R.C.A.; VIEIRA, C.M.B. Estimativa da recarga do aquífero Urucuia da sub-bacia do rio das Fêmeas - Oeste da Bahia, utilizando separação de hidrogramas. In: $1^{\circ}$ CONGRESSO SOBRE APRO- 
VEITAMENTO E GESTÃO DE RECURSOS HÍDRICOS EM PAÍSES DE IDIOMA PORTUGUÊS, Rio de Janeiro - RJ, 2000, Anais..., 11 pp. POMPEU J., RODRIGUES Z.R.C. Estudo Hidrogeológico da Bacia do Rio das Fêmeas. In: Simpósio de Água e Desenvolvimento Sustentável no Oeste Baiano, 1, 2002, Anais..., CD-ROM.

RODRIGUES, Z.R.C.; MAIA, P.H.P.; LIMA, C.E.S.; ARAÚJO, V.M.; CRUZ, L.V.M. Hidrodinâmica do Sistema Aquífero Urucuia e seu Rebatimento para a Gestão da Água na Região Oeste do Estado da Bahia. In: CONGRESSO INTERNACIONAL DE Meio Ambiente Subterrâneo, 1, 2009, São Paulo-SP, Anais..., p.1-14.

SANTOS, J.P. Avaliação dos parâmetros hidrodinâmicos do Aquífero Urucuia. Relatório Final. ANA/GEF/PNUMA/OEA, Superintendência de Recursos Hídricos (SRH). Salvador- BA. 2002. 75p.

SCHUSTER, H.D.M. Modelagem de Fluxo Subterrâneo com Vistas à Definição de Parâmetros para Outorga de Mananciais Subterrâneos na Bacia Hidrográfica do Rio de Cachorro Oeste do Estado da Bahia. Relatório Final. Campina GrandePB: 2003. Universidade Federal da Paraíba UFPB. 113 pp.
SCHUSTER, H.D.M.; SILVA, F.F.; TEIXEIRA, S.L.; BATISTA, L.H.G.; FREITAS, W.A. Estudos hidrogeológicos do aquífero Urucuia no Oeste baiano para obtenção de parâmetros nas outorgas de mananciais subterrâneos. In: CONGRESSO BRASILEIRO DE ÁGUAS SUBTERRÂNEAS, 12, Florianópolis-SC, 2002, Anais..., 15 pp.

SGARBI, G.N.C. Geologia da Formação Areado. Cretáceo Inferior a Médio da Bacia Sanfranciscana, Oeste do estado de Minas Gerais. Rio de Janeiro-RJ, 1989. 324p. Dissertação de mestrado. Universidade Federal do Rio de Janeiro.

SPIGOLON A.L.D.; ALVARENGA C.J.S. Fáceis e elementos arquiteturais resultantes de mudanças climáticas em um ambiente desértico: Grupo Urucuia (Neocretáceo), Bacia Sanfranciscana. Revista Brasileira de Geociências, 32(4): 579-586. 2002.

TSCHIEDEL M.W. Aplicação de estudo geofísico como contribuição ao conhecimento da tectônica da Sub-Bacia Urucuia. Brasília-DF, 2004. 76p. Dissertação de Mestrado ${ }^{\circ}$ 185. IG-UnB. 